\title{
Oxygen and carbon dioxide targets during and after resuscitation of cardiac arrest patients
}

\author{
M. B. Skrifvars ${ }^{1 *}$, T. M. Olasveengen ${ }^{2}$ and Giuseppe Ristagno ${ }^{3}$
}

(c) 2018 Springer-Verlag GmbH Germany, part of Springer Nature and ESICM

\section{Introduction}

The goal of cardiopulmonary resuscitation (CPR) may be summarized as an effort to rapidly restore spontaneous circulation and to prevent hypoxic ischaemic brain injury (HIBI) [1]. The key determinant of tissue oxygenation during CPR is high quality chest compressions [2]. With ventilation the aim is to increase oxygen content of arterial blood whilst decreasing arterial carbon dioxide $\left(\mathrm{paCO}_{2}\right)$, alleviating respiratory acidosis. On the other hand, reactive oxygen species play an important part in the development of HIBI, thus avoiding extreme hyperoxia seems intuitive [3]. The relationship between arterial and tissue oxygenation and ventilation during CPR is complex. Conclusive evidence of optimal oxygen or carbon dioxide targets are scarce, but taking into account the pathophysiological changes may guide clinical practice (Fig. 1). In the current commentary we discuss what is known about the optimal oxygen and carbon dioxide targets during and immediately after cardiac arrest (CA) and how we may achieve them.

\section{Changes in oxygen and carbon dioxide in cardiac arrest}

Cardiac arrest causes an abrupt cessation in the delivery of oxygen, and while many organs may survive hours with ischemia, the brain's survival is measured in minutes. With high metabolic rates and limited energy stores, the heart and brain deplete their tissue oxygen within seconds [4], and glucose and glycogen reserves within

${ }^{*}$ Correspondence: markus.skrifvars@hus.fi

${ }^{1}$ Department of Emergency Care and Services, University of Helsinki and Helsinki University Hospital, Helsinki, Finland

Full author information is available at the end of the article minutes [5]. There are limited observations of blood and tissue oxygenation and carbon dioxide levels during untreated CA in humans, but these levels are likely influenced by the pre-arrest factors that determine oxygen supply and demand. An asphyxial arrest is expected to cause lower tissue oxygenation and hypercapnia compared to an arrest from a sudden arrhythmia, as tissue metabolism has continued with decreasing oxygen supply. Conversely, conditions with decreased oxygen demand, i.e. hypothermia, will likely yield higher initial tissue oxygenation and lower carbon dioxide compared to a normothermic arrest.

In the first minutes after CA patients may have abnormal brainstem mediated breathing, commonly referred to as "agonal breathing". Prospective studies have reported agonal breathing in about a third of witnessed out-of-hospital cardiac arrests (OHCA), and found it to be associated with improved survival [6]. This phenomenon has also been observed in animal experimental studies, where this agonal respiration has been shown to produce both forward blood flow and ventilation [7]. Although the effectiveness of agonal breathing is uncertain, consistent observations that gasping patients have better outcomes suggest positive effects on circulation and/or gas exchange during CA.

\section{Oxygen and carbon dioxide during cardiopulmonary resuscitation}

Two elegant studies by Spindelboeck and colleagues investigated oxygen and carbon dioxide levels in arterial blood during CPR in patients ventilated with $100 \%$ oxygen, describing different oxygen levels ranging from hypoxia to hyperoxia [8,9]. The study showed that patients with hypoxia had lower survival than those 


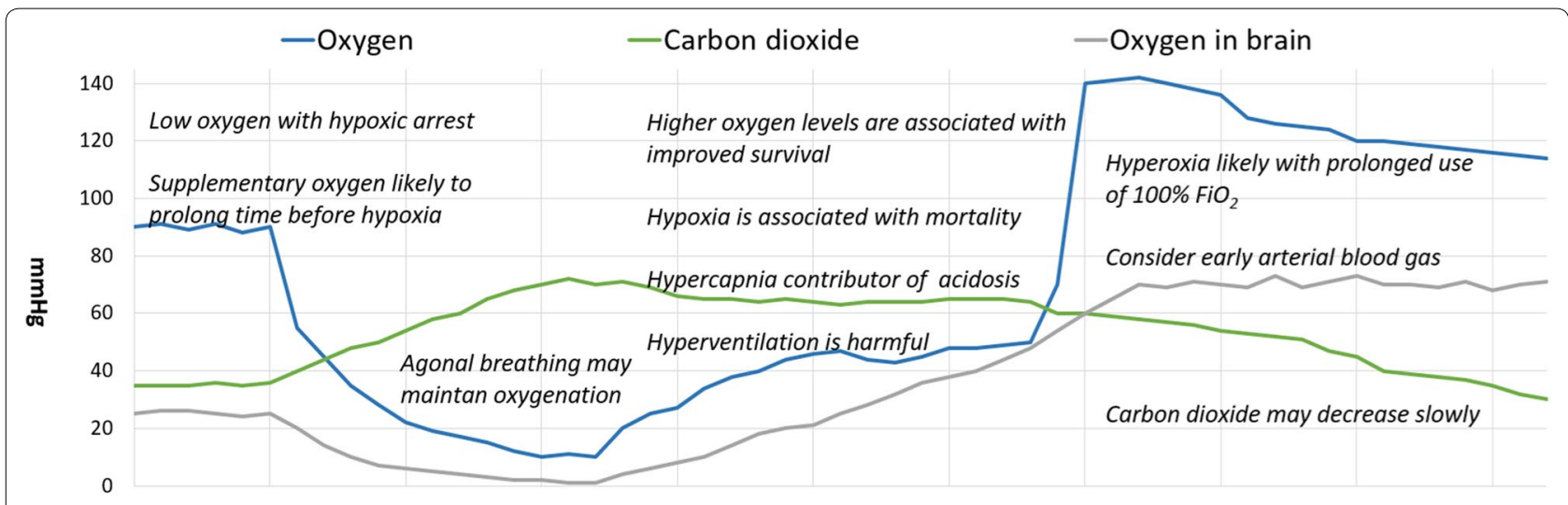

\begin{tabular}{l|l|l|l} 
Pre-arrest & Untreated cardiac arrest & Chest compressions and ventilation $\quad$ Return of spontaneuous circulation
\end{tabular}

Fig. 1 An approximate depiction of changes in oxygen and carbon dioxide in the arterial blood as well as oxygen in brain tissue before with management aspects, during and immediately after cardiac arrest

with normoxia or hyperoxia, but they could not find any association between oxygenation and bystander CPR or delay from collapse to CPR. Neither did they show any link between extreme intra-arrest hyperoxia and worse outcomes. Animal data, on the other hand, suggest that ventilation with $50 \%$ oxygen may be enough to correct hypoxia and result in similar levels of brain tissue oxygen compared to $100 \%$ oxygen [10]. Theoretically, such a practice could decrease the rate of extreme hyperoxia and should be studied further. One problem is the lack of means to monitor intra-arrest oxygenation, since obtaining an arterial blood gas (ABG) reading appears feasible only in the intensive care unit (ICU) and in some selected pre-hospital systems. It may also be argued that venous samples could be more reflective of tissue oxygenation than arterial samples. Recent studies have addressed intra-arrest brain oxygenation monitoring with near infrared spectroscopy (NIRS). Thus far, the evidence does not suggest any role for NIRS for tailoring oxygen use during CPR.

The studies by Spindelboek also showed that most patients are hypercapnic during CPR and have severe respiratory acidosis $[8,9]$. They did not, however, find any association between the severity of hypercapnia or acidosis with outcome. Severe acidosis causes negative inotropy and vasodilatation which intuitively appears harmful. Ventilation with higher minute volumes can decrease $\mathrm{paCO}_{2}$ quicker and normalize $\mathrm{pH}$ but this has inadvertent effects. An important study by Aufderheide and colleagues showed that hyperventilation during CPR increases intra-thoracic pressure, decrease coronary perfusion pressure and worsens outcome [11]. By decreasing the frequency of ventilations, cardiac output and pulmonary blood flow may be increased without compromise of arterial oxygen content or acid-base balance [12]. Thus, the recommendation to ventilate cardiac arrest patients with $100 \%$ oxygen with a ventilation rate of 12 and tidal volume of $500 \mathrm{ml}$ appears justified, and in many OHCA cases this will correct the hypoxia; the effect on $\mathrm{paCO}_{2}$ appears variable.

\section{Oxygen and carbon dioxide targets immediately after ROSC}

A sharp increase in mean arterial blood pressure immediately after ROSC after CA has been commonly reported. This will also increase oxygen levels in brain tissue. The goal at this stage is to monitor oxygenation and to target normoxia [13]. In the majority of patients, the percentage of inspired oxygen $\left(\mathrm{FiO}_{2}\right)$ can be decreased. Prolonged ventilation with a $\mathrm{FiO}_{2}$ of $100 \%$ is a common cause of extreme hyperoxia [14]. Even though conclusive evidence does not exist, there is little reason not to avoid extreme hyperoxia at this stage. In the only randomized study conducted to date, Kuisma and colleagues showed an increase in neuron specific enolase (biomarker of brain injury) in one subset of patients ventilated with $100 \%$ compared to $30 \%$ [15]. Monitoring oxygenation is difficult in the pre-hospital setting, though a small pilot trial using peripheral oxygen saturation to titrate oxygen found this strategy resulted in frequent hypoxia [16]. Thus, there is a need for obtaining an arterial blood gas reading as soon as possible.

In most cases, $\mathrm{paCO}_{2}$ is elevated after ROSC. This will correct itself over the first hour and there is little need to speed up this process; some clinical data even suggest associations between moderate hypercapnia and 
improved outcome [17]. Indeed $\mathrm{paCO}_{2}$ is an important regulator of cerebral blood flow and moderate hypercapnia can, according to experimental studies and one clinical pilot study, increase cerebral oxygenation and attenuate ischaemia-reperfusion injury due to mitigation of oxidative stress $[18,19]$. Animal data also suggest antiepileptic effects with moderate hypercapnia and potential reduction in the excitotoxicity induced by high levels of excitatory neurotransmitters such as the amino acid glutamate [20]. Two ongoing large RCTs, one on oxygen use during tranportation of OHCA patients (the EXACT trial, NCT3138005) and one on targeting mild hypercapnia during the first $24 \mathrm{~h}$ of ICU care (the TAME trial, NCT3114033) are ongoing and are likely to provide more conclusive evidence. Until conclusive clinical data are made available, the current recommendation is to aim for normoventilation with a $\mathrm{paO}_{2}$ of $4.5-6.0 \mathrm{kPa}$ [13].

\section{Author details}

${ }^{1}$ Department of Emergency Care and Services, University of Helsinki and Helsinki University Hospital, Helsinki, Finland. ${ }^{2}$ Department of Anesthesiology, Oslo University Hospital, Oslo, Norway. ${ }^{3}$ Neurosurgery I Unit, Neuro Center, Humanitas Research Hospital, Rozzano, Italy.

\section{Compliance with ethical standards}

\section{Conflicts of interest}

Markus Skrifvars has received a lecture fee from Covidien (Invos).

Received: 10 September 2018 Accepted: 7 November 2018 Published online: 12 November 2018

\section{References}

1. Nolan JP, Berg RA, Callaway CW, Morrison LJ, Nadkarni V, Perkins GD, Sandroni C, Skrifvars MB, Soar J, Sunde K, Cariou A (2018) The present and future of cardiac arrest care: international experts reach out to caregivers and healthcare authorities. Intensive Care Med 44:823-832

2. Imberti R, Bellinzona G, Riccardi F, Pagani M, Langer M (2003) Cerebral perfusion pressure and cerebral tissue oxygen tension in a patient during cardiopulmonary resuscitation. Intensive Care Med 29:1016-1019

3. Neumar RW (2011) Optimal oxygenation during and after cardiopulmonary resuscitation. Curr Opin Crit Care 17:236-240

4. MacMillan V, Siesjo BK (1971) Critical oxygen tensions in the brain. Acta Physiol Scand 82:412-414

5. Siesjo BK, Carlsson C, Hagerdal M, Nordstrom CH (1976) Brain metabolism in the critically ill. Crit Care Med 4:283-294
6. Debaty G, Labarere J, Frascone RJ, Wayne MA, Swor RA, Mahoney BD, Domeier RM, Olinger ML, O'Neil BJ, Yannopoulos D, Aufderheide TP, Lurie KG (2017) Long-term prognostic value of gasping during out-of-hospital cardiac arrest. J Am Coll Cardiol 70:1467-1476

7. Ristagno G, Tang W, Sun S, Weil MH (2007) Spontaneous gasping produces carotid blood flow during untreated cardiac arrest. Resuscitation 75:366-371

8. Spindelboeck W, Schindler O, Moser A, Hausler F, Wallner S, Strasser C, Haas J, Gemes G, Prause G (2013) Increasing arterial oxygen partial pressure during cardiopulmonary resuscitation is associated with improved rates of hospital admission. Resuscitation 84:770-775

9. Spindelboeck W, Gemes G, Strasser C, Toescher K, Kores B, Metnitz P, Haas J, Prause G (2016) Arterial blood gases during and their dynamic changes after cardiopulmonary resuscitation: a prospective clinical study. Resuscitation 106:24-29

10. Nelskyla A, Nurmi J, Jousi M, Schramko A, Mervaala E, Ristagno G, Skrifvars MB (2017) The effect of 50\% compared to $100 \%$ inspired oxygen fraction on brain oxygenation and post cardiac arrest mitochondrial function in experimental cardiac arrest. Resuscitation 116:1-7

11. Aufderheide TP, Sigurdsson G, Pirrallo RG, Yannopoulos D, McKnite S, von Briesen C, Sparks CW, Conrad CJ, Provo TA, Lurie KG (2004) Hyperventilation-induced hypotension during cardiopulmonary resuscitation. Circulation 109:1960-1965

12. Yannopoulos D, Tang W, Roussos C, Aufderheide TP, Idris AH, Lurie KG (2005) Reducing ventilation frequency during cardiopulmonary resuscitation in a porcine model of cardiac arrest. Respir Care 50:628-635

13. Soar J, Nolan JP, Bottiger BW, Perkins GD, Lott C, Carli P, Pellis T, Sandroni C, Skrifvars MB, Smith GB, Sunde K, Deakin CD, Adult Advanced Life Support Section C (2015) European Resuscitation Council guidelines for resuscitation 2015: section 3. Adult advanced life support. Resuscitation 95:100-147

14. Nelskyla A, Parr MJ, Skrifvars MB (2013) Prevalence and factors correlating with hyperoxia exposure following cardiac arrest-an observational single centre study. Scand J Trauma Resusc Emerg Med 21:35

15. Kuisma M, Boyd J, Voipio V, Alaspaa A, Roine RO, Rosenberg P (2006) Comparison of 30 and the $100 \%$ inspired oxygen concentrations during early post-resuscitation period: a randomised controlled pilot study. Resuscitation 69:199-206

16. Young P, Bailey M, Bellomo R, Bernard S, Dicker B, Freebairn R, Henderson S, Mackle D, McArthur C, McGuinness S, Smith T, Swain A, Weatherall M, Beasley R (2014) HyperOxic Therapy OR NormOxic Therapy after out-ofhospital cardiac arrest (HOT OR NOT): a randomised controlled feasibility trial. Resuscitation 85:1686-1691

17. Vaahersalo J, Bendel S, Reinikainen M, Kurola J, Tiainen M, Raj R, Pettila V, Varpula T, Skrifvars MB, Group FS (2014) Arterial blood gas tensions after resuscitation from out-of-hospital cardiac arrest: associations with longterm neurologic outcome. Crit Care Med 42:1463-1470

18. Eastwood GM, Young PJ, Bellomo R (2014) The impact of oxygen and carbon dioxide management on outcome after cardiac arrest. Curr Opin Crit Care 20:266-272

19. Shoja MM, Tubbs RS, Shokouhi G, Loukas M, Ghabili K, Ansarin K (2008) The potential role of carbon dioxide in the neuroimmunoendocrine changes following cerebral ischemia. Life Sci 83:381-387

20. Tolner EA, Hochman DW, Hassinen P, Otahal J, Gaily E, Haglund MM, Kubova H, Schuchmann S, Vanhatalo S, Kaila K (2011) Five percent CO(2) is a potent, fast-acting inhalation anticonvulsant. Epilepsia 52:104-114 